\title{
BMJ
}

\section{Efficacy of drug treatments for generalised anxiety disorder: systematic review and meta-analysis}

\author{
David Baldwin, professor of psychiatry and honorary consultant psychiatrist, ${ }^{1}$ Robert Woods, senior research \\ executive, ${ }^{2}$ Richard Lawson, statistician, ${ }^{2}$ David Taylor, professor of psychopharmacology ${ }^{3}$
}

University of Southampton Faculty of Medicine, University Department of Psychiatry, Academic Centre, Southampton S014 3DT, UK

${ }^{2}$ Complete Medical Group, Macclesfield SK10 1AQ

${ }^{3}$ King's College London, London SE1 9NH

Correspondence to: D Baldwin D.S.Baldwin@soton.ac.uk

Cite this as: $B M J$ 2011;342:d1199 doi:10.1136/bmj.d1199

\section{ABSTRACT}

Objective To appraise the evidence for comparative efficacy and tolerability of drug treatments in patients with generalised anxiety disorder.

Design Systematic review of randomised controlled trials. Primary Bayesian probabilistic mixed treatment metaanalyses allowed pharmacological treatments to be ranked for effectiveness for each outcome measure, given as percentage probability of being the most effective treatment. Secondary frequentist mixed treatment metaanalyses conducted with random effects model; effect size reported as odds ratio and $95 \%$ confidence interval. Data sources Medline, Embase, BIOSIS, PsycINFO, Health Economic Evaluations Database, National Health Service Economic Evaluation Database, and Database of Abstracts of Reviews of Effects via DataStar, and Cochrane Database of Systematic Reviews via Cochrane Library (January 1980 to February 2009).

Eligibility criteria Double blind placebo controlled randomised controlled trials; published systematic reviews and meta-analyses of randomised controlled trials. Randomised controlled trials including adult participants (aged $\geq 18$ ) receiving any pharmacological treatment for generalised anxiety disorder.

Data abstraction methods Titles or abstracts reviewed initially, followed by review of full text publications for citations remaining after first pass. A three person team conducted screening; an independent reviewer checked a random selection (10\%) of articles screened. Data extracted for meta-analysis were also independently reviewed.

Main outcome measures Proportion of participants experiencing $\geq 50 \%$ reduction from baseline score on Hamilton anxiety scale (HAM-A) (response), proportion with final HAM-A score $\leq 7$ (remission), proportion withdrawing from trial because of adverse events (tolerability).

Results The review identified 3249 citations, and 46 randomised controlled trials met inclusion criteria; 27 trials contained sufficient or appropriate data for inclusion in the analysis. Analyses compared nine drugs (duloxetine, escitalopram, fluoxetine, lorazepam, paroxetine, pregabalin, sertraline, tiagabine, and venlafaxine). In the primary probabilistic mixed treatment meta-analyses, fluoxetine was ranked first for response and remission (probability of $62.9 \%$ and $60.6 \%$, respectively) and sertraline was ranked first for tolerability (49.3\%). In a subanalysis ranking treatments for generalised anxiety disorder currently licensed in the United Kingdom, duloxetine was ranked first for response (third across all treatments; $2.7 \%$ ), escitalopram was ranked first for remission (second across all treatments; $26.7 \%$ ), and pregabalin was ranked first for tolerability (second across all treatments; $7.7 \%$ ).

Conclusions Though the frequentist analysis was inconclusive because of a high level of uncertainty in effect sizes (based on the relatively small number of comparative trials), the probabilistic analysis, which did not rely on significant outcomes, showed that fluoxetine (in terms of response and remission) and sertraline (in terms of tolerability) seem to have some advantages over other treatments. Among five UK licensed treatments, duloxetine, escitalopram, and pregabalin might offer some advantages over venlafaxine and paroxetine.

\section{INTRODUCTION}

Generalised anxiety disorder is a chronic or relapsing condition characterised by persistent and pervasive worrying and tension, ${ }^{1}$ which causes substantial personal distress and imposes a considerable economic burden. ${ }^{2}$ Anxiety disorders are among the most prevalent of mental disorders, and generalised anxiety disorder is the most common impairing anxiety disorder in primary care. ${ }^{3}$ The degree of disability attributable to generalised anxiety disorder compares with that of major depression and is similar to that of chronic physical illnesses such as peptic ulceration, arthritis, asthma, and diabetes mellitus. ${ }^{4}$

Current guidelines for the pharmacological management of generalised anxiety disorder tend to recommend first line treatment with a selective serotonin reuptake inhibitor or pregabalin. ${ }^{5-7}$ Updated guidelines from the National Institute for Health and Clinical Excellence (NICE) were published in January 2011. Published systematic reviews and meta-analyses have compared the effectiveness of psychotropic drugs for treating generalised anxiety disorder. ${ }^{8-10}$ These studies, however, compared the effectiveness of only 
selected treatments (such as benzodiazepines ${ }^{810}$ ) rather than all available treatments.

In this systematic review we compared the efficacy and tolerability of all drug treatments for generalised anxiety disorder by combining data from published randomised controlled trials. We also carried out a subanalysis comparing the five drugs currently licensed for generalised anxiety disorder in the United Kingdom (duloxetine, escitalopram, paroxetine, pregabalin, and venlafaxine). The extracted data were combined in a series of mixed treatment meta-analyses, which incorporated evidence from trials indirectly comparing drugs with a common comparator (such as placebo) as well as evidence from direct comparisons of drugs (that is, head to head trials). ${ }^{11}$ Application of this approach within a Bayesian framework enabled treatments to be ranked in terms of the probability of each treatment being the first or most effective for each outcome measure.

\section{METHODS}

\section{Literature search}

We conducted a systematic review of the literature on the treatment of generalised anxiety disorder. To be eligible for inclusion studies had to be double blind, placebo controlled, phase II, III, or IV randomised controlled trials of any duration; published systematic reviews and meta-analyses of randomised controlled trials; and randomised controlled trials in adults (aged $\geq 18$ ) receiving any active drug treatment for generalised anxiety disorder

We retrieved published randomised controlled trials, systematic reviews, and meta-analyses from January 1980 to February 2009 by conducting a systematic search of mental and general health databases (Medline, Embase, BIOSIS, PsycINFO, Health Economic Evaluations Database (HEED), National Health Service Economic Evaluation Database (NHSEED), and Database of Abstracts of Reviews of Effects (DARE)) using DataStar on the internet, ${ }^{12}$ and the Cochrane Database of Systematic Reviews using the Cochrane Library on the internet. ${ }^{13}$ The Medline, Embase, BIOSIS, and PsycINFO searches were conducted on 30 January 2009; the HEED, NHSEED, and DARE searches were conducted on 4 February 2009; the Cochrane Library was searched on 2 February 2009. We used a comprehensive search strategy, including terms for anxiety and generalised anxiety disorder, using both UK and American spellings, and incorporated specific filters for retrieving randomised controlled trials, meta-analyses, and systematic reviews in humans. The full search strategy is shown in appendix 1 on bmj.com. Hand searching was not performed, but reference lists of identified systematic reviews, meta-analyses, and pooled analyses were reviewed to identify further studies. Unpublished studies were not specifically sought but were included if they were identified from the reference lists of published systematic reviews or meta-analyses.

\section{Data selection}

Identified articles were screened to ensure they met pre-determined inclusion criteria. Each reviewer was given a checklist of inclusion criteria specified in the systematic review protocol, and a structured Excel spreadsheet was used to ensure uniformity of appraisal for each study. Titles or abstracts, or both, for all identified citations were reviewed initially, followed by a second review stage of full text publications for citations remaining after the first pass. A three person team reviewed the articles at first and second pass, and an independent reviewer checked a random selection $(10 \%)$ of filtered articles for consistency.

We used a positive exclusion method, whereby we excluded only those publications that did not meet one or more of the inclusion criteria.

\section{Data extraction}

The structured Excel spreadsheet onto which data were extracted ensured uniformity of appraisal for each study and capture of all relevant data. All data extracted for meta-analysis were also independently reviewed. Extracted data consisted of study characteristics (such as treatments and doses, method for diagnosis of generalised anxiety disorder, duration, and study location) and relevant outcomes (such as anxiety scores at baseline and end of study, and proportions of responders and remitters) (see table A on bmj.com).

\section{Outcome measures}

There were three primary outcomes: response and remission were considered as measures of efficacy, and, because of the absence of a rating scale for side effects across studies, we used withdrawals because of adverse events as the measure of tolerability. "Response" was defined as the proportion of patients who experienced a reduction of at least $50 \%$ from their baseline score on the Hamilton anxiety scale (HAMA), and "remission" was defined as the proportion of patients with a final score $\leq 7$. These definitions for response and remission are consistent with commonly

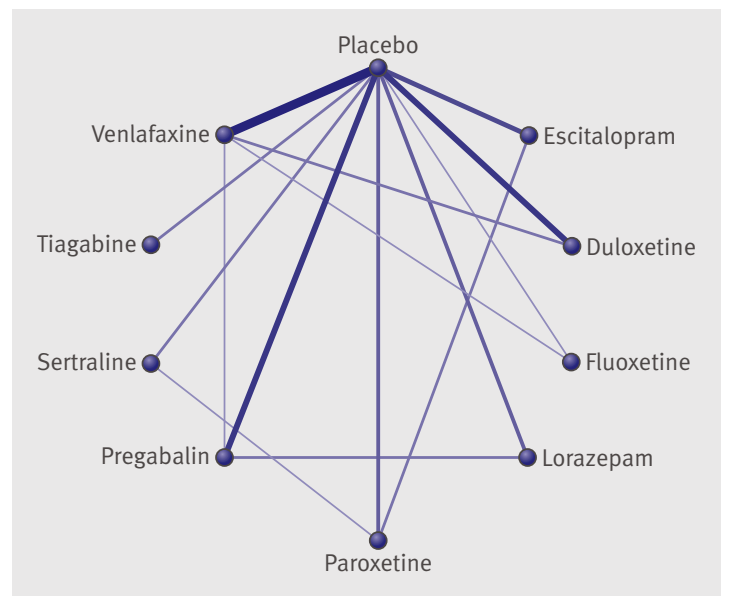

Fig 1 | Eligible network comparisons between all treatments, with increasing thickness of lines indicating increasing number of direct comparisons 
Table 1|Probabilistic analysis showing ranking of treatments by outcome measure according to currently available evidence for generalised anxiety disorder

\begin{tabular}{|c|c|c|c|}
\hline Ranking & Response* & Remission $†$ & Withdrawalł \\
\hline 1 & Fluoxetine§ & Fluoxetine§ & Sertraline§ \\
\hline 2 & Lorazepam§ & Escitalopram & Pregabalin \\
\hline 3 & Duloxetine & Venlafaxine & Fluoxetine§ \\
\hline 4 & Sertraline§ & Paroxetine & Paroxetine \\
\hline 5 & Paroxetine & Sertraline§ & Tiagabine§ \\
\hline 6 & Pregabalin & Duloxetine & Venlafaxine \\
\hline 7 & Venlafaxine & Tiagabine§ & Escitalopram \\
\hline 8 & Escitalopram & NA & Duloxetine \\
\hline 9 & Tiagabine§ & NA & Lorazepam§ \\
\hline
\end{tabular}

$N A=$ not available (not all studies reported on this outcome for all drugs).

*Proportion of patients who experienced reduction of $\geq 50 \%$ from their baseline Hamilton anxiety scale score. †Proportion of patients with final HAM-A score $\leq 7$.

łPercentage of patients withdrawing from study because of adverse events.

$\S$ Not licensed for generalised anxiety disorder in UK.

used thresholds in clinical studies and those reported in the 2007 National Institute for Health and Clinical Excellence guideline. ${ }^{7} \mathrm{We}$ extracted and analysed data on withdrawals when these were reported but did not specifically obtain these for studies that did not report this outcome: the withdrawals outcome was defined as the percentage of patients withdrawing from the trial because of adverse events.

\section{Statistical analysis}

Analyses were performed on data that were explicitly reported in the individual papers, with no imputations for data that were not reported. When available, we analysed the intention to treat population; when this was not possible, we used data from the last observation carried forward.

The network of treatment comparisons (fig 1) formed the basis for two sets of mixed treatment meta-analyses (described below), which combine both direct and indirect evidence in a single model. ${ }^{11}$

\section{Primary analyses}

The primary analyses were conducted with a Bayesian Markov chain Monte Carlo method and fitted with the Bayesian software in WinBUGS (Medical Research Council Biostatistics Unit, Cambridge, UK). ${ }^{14}$ For the analyses in WinBUGS, every sample consisted of 20000 iterations with an initial burn-in period of 1000 iterations. The model framework, stratified by study, included univariate random effects to allow for apparent heterogeneity between studies in the treatment comparison effects. The probability of the outcome was modelled with a binomial distribution, as described in detail elsewhere,${ }^{15}$ and each pair of treatments was compared by estimating the odds ratio of the outcome. Each study within each random effects meta-analysis had a weight based on the variation within the study. We assumed that each of the log odds ratios had been sampled from a normal distribution and that treatment effects are wholly exchangeable within studies. The model was checked for convergence by considering the relevant kernel density plots and was also checked diagnostically through the autocorrelation plots within WinBUGS, which showed that throughout the iterative process the autocorrelation was satisfactorily reduced to a nominal amount. We chose "vague prior parameters," given the relatively novel analytical approach, ${ }^{16}$ especially within this area. The prior parameters for the model were fixed because of the goodness of fit of data to the model and the fact that the prior parameters were relatively vague. The initial values used were varied and tested in the models, with both specified and auto-generated data. In all cases the effect estimates converged to a common figure.

A benefit of this modelling technique was that treatments could be ranked by using probabilistic statements, and the probability of each treatment being ranked first/most effective could be determined for each outcome measure. We carried out a subanalysis of drugs licensed for the treatment of generalised anxiety disorder in the UK at the time our analysis was conducted.

\section{Secondary analyses}

The secondary analyses were carried out in a frequentist framework in Stata version 9 (StataCorp, College Station, Texas). These were designed to support the validity of any findings identified in the primary probabilistic analyses. The model framework, stratified by study, included random effects to allow for apparent heterogeneity between studies in treatment comparison effects (assumed to be consistent for each comparison). All outcome measures considered in the secondary analyses (response, remission, and withdrawals because of adverse events) were binary so we reported the odds ratio as the summary statistic. Differences between treatments were tested for significance at the $95 \%$ significance level.

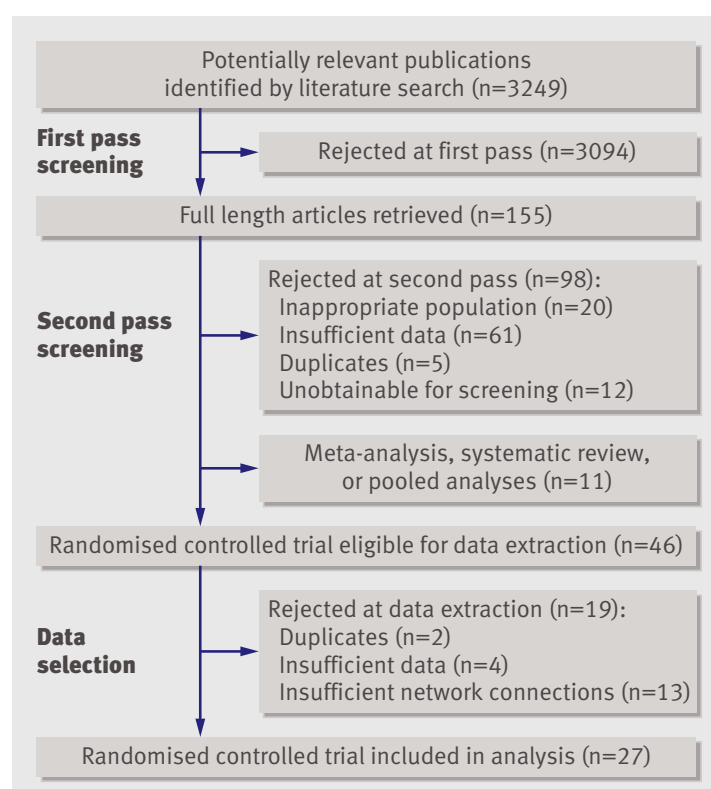

Fig 2 Progression of articles through each stage of systematic review 
We tested the validity of the mixed treatment model by comparing the consistency of results between the mixed treatment meta-analyses and the direct comparison meta-analyses of the UK licensed treatments versus all active treatments of interest and all active treatments versus placebo. This was done by calculating the difference between the odds ratios for each pairwise comparison (mixed treatment comparison - direct comparison) and conducting an unpaired $t$ test to identify differences in effect estimate between the two models. The results were considered significant (that is, inconsistent) if the 95\% confidence interval did not contain zero. Ideally, the difference in the odds ratio should be zero (that is, results of the direct and indirect meta-analyses are identical) (see table B on bmj.com.).

\section{RESULTS}

Data selection

Figure 2 shows selection process for articles. The systematic search identified 3249 potentially relevant publications. First pass screening eliminated 3094, leaving 155 full text articles to be reviewed at the second pass stage. Of these, 46 trials met the inclusion criteria, but only 27 contained sufficient or appropriate data to be included in the analysis. ${ }^{17-43}$ Of the 19 trials rejected at data selection, two presented duplicate data, ${ }^{2339}$ four presented insufficient data for extra ction, ${ }^{44-47}$ and 13 presented insufficient network connections (that is, the only randomised controlled trials for a particular drug or the comparator in the study was inappropriate). ${ }^{48-60}$ Table A on bmj.com gives details of the 27 included trials.

The data extracted from these 27 publications allowed analyses to be performed for nine treatments: duloxetine, escitalopram, fluoxetine, lorazepam, paroxetine, pregabalin, sertraline, tiagabine, and venlafaxine. Eight of the trials identified examined venlafaxine, five escitalopram, five pregabalin, five paroxetine, five duloxetine, three sertraline, two lorazepam, two tiagabine, and one fluoxetine (containing links to two treatments of interest).
Of the included studies, 26 were published in 2001 or later and one was published in 1999. Most participating patients were from the European Union or the United States. Twenty three studies reported response outcomes, 23 reported data on withdrawals because of adverse events, and 14 studies contained information on remission.

\section{Mixed treatment meta-analyses}

We performed two different mixed treatment metaanalyses: the primary analysis consisted of a Bayesian probabilistic analysis and the secondary analysis used frequentist methods. The network of treatments for generalised anxiety disorder on which both sets of analyses were based (see fig 1 allowed both direct evidence (from head to head trials) and evidence from trials indirectly comparing drugs with a common comparator (such as placebo) to be combined. Figure 3 shows quantification of the direct evidence used to inform the network of eligible comparisons, which relied heavily on comparison of active treatment with placebo.

Table 1 shows the results of the primary analysis. In these analyses, drug treatments were ranked in terms of effectiveness for each of the three outcome measures. Figure 4 shows the percentage probability of each treatment being ranked the most effective for the three outcome measures. Probabilistic analyses also allowed the probability of each active treatment being ranked at each position (that is, first to ninth) to be calculated for each outcome (fig 5).

Tables 2-4 present the results of the secondary analyses, which compared each UK licensed treatment for generalised anxiety disorder with each other drug treatment for each of the three outcomes.

The appropriateness of the model framework used in the secondary analyses was supported by the test for consistency between the results of the direct comparison meta-analyses and those of the mixed treatment meta-analyses (see table B on bmj.com). Although there were 28 possibilities for direct treatment comparisons, based on the number of treatments investigated (fig 3), only six included studies provided direct

\begin{tabular}{|c|c|c|c|c|c|c|c|c|c|c|}
\hline & Duloxetine & Escitalopram & Fluoxetine & Lorazepam & Paroxetine & Placebo & Pregabalin & Sertraline & Tiagabine & Venlafaxine \\
\hline Duloxetine & & - & - & - & - & 5 & - & - & - & 2 \\
\hline Escitalopram & & & - & - & 2 & 4 & - & - & - & - \\
\hline Fluoxetine & & & & - & - & 1 & - & - & - & 1 \\
\hline Lorazepam & & & & & - & 3 & 2 & - & - & - \\
\hline Paroxetine & & & & & & 3 & - & 1 & - & - \\
\hline Placebo & & & & & & & 5 & 2 & 2 & 8 \\
\hline Pregabalin & & & & & & & & - & - & 1 \\
\hline Sertraline & & & & & & & & & - & - \\
\hline Tiagabine & & & & & & & & & & - \\
\hline Venlafaxine & & & & & & & & & & \\
\hline
\end{tabular}


Table $2 \mid$ Results of secondary mixed treatment meta-analyses comparing UK licensed treatments with other treatments in terms of response (proportion of patients who experienced reduction of $\geq 50 \%$ from baseline in Hamilton anxiety scale score). Figures are odds ratios* $(95 \%$ confidence intervals)

\begin{tabular}{|c|c|c|c|c|c|c|c|c|c|}
\hline $\begin{array}{l}\text { UK licensed } \\
\text { treatments } \\
\text { and placebo }\end{array}$ & Duloxetine & Escitalopram & Fluoxetine & Lorazepam & Paroxetine & Pregabalin & Sertraline & Tiagabine & Venlafaxine \\
\hline Duloxetine & - & $\begin{array}{c}1.45 \\
\text { (0.68 to } 3.18)\end{array}$ & $\begin{array}{c}0.84 \\
\text { (0.35 to } 1.97)\end{array}$ & $\begin{array}{c}0.87 \\
(0.45 \text { to } 1.72)\end{array}$ & $\begin{array}{c}1.06 \\
(0.51 \text { to } 2.22)\end{array}$ & $\begin{array}{c}1.12 \\
(0.75 \text { to } 1.67)\end{array}$ & $\begin{array}{c}1.01 \\
(0.59 \text { to } 1.73)\end{array}$ & $\begin{array}{c}1.62 \dagger \\
\text { (1.01 to } 2.55)\end{array}$ & $\begin{array}{c}1.01 \\
(0.76 \text { to } 1.35)\end{array}$ \\
\hline Escitalopram & $\begin{array}{c}0.67 \\
(0.32 \text { to } 1.47)\end{array}$ & - & $\begin{array}{c}0.39 \\
(0.1 \text { to } 1.64)\end{array}$ & $\begin{array}{c}0.59 \\
(0.23 \text { to } 1.55)\end{array}$ & $\begin{array}{c}0.96 \\
(0.29 \text { to } 1.63)\end{array}$ & $\begin{array}{c}0.76 \\
(0.34 \text { to } 1.7)\end{array}$ & $\begin{array}{c}0.68 \\
(0.29 \text { to } 1.59)\end{array}$ & $\begin{array}{c}1.09 \\
(0.48 \text { to } 2.46)\end{array}$ & $\begin{array}{c}0.77 \\
\text { (0.35 to } 1.65)\end{array}$ \\
\hline Paroxetine & $\begin{array}{c}0.95 \\
\text { (0.46 to } 1.98)\end{array}$ & $\begin{array}{c}0.9 \\
(0.45 \text { to } 1.78)\end{array}$ & $\begin{array}{c}0.57 \\
\text { (0.13 to } 2.36)\end{array}$ & $\begin{array}{c}0.83 \\
(0.33 \text { to } 2.06)\end{array}$ & - & $\begin{array}{c}1.08 \\
\text { (0.5 to } 2.32)\end{array}$ & $\begin{array}{c}0.96 \\
\text { (0.42 to } 2.16)\end{array}$ & $\begin{array}{c}1.54 \\
\text { (0.69 to } 3.33)\end{array}$ & $\begin{array}{c}1.09 \\
\text { (0.51 to } 2.23)\end{array}$ \\
\hline Pregabalin & $\begin{array}{c}0.89 \\
\text { (0.6 to } 1.32)\end{array}$ & $\begin{array}{c}1.3 \\
(0.59 \text { to } 2.9)\end{array}$ & $\begin{array}{c}0.74 \\
(0.29 \text { to } 1.86)\end{array}$ & $\begin{array}{c}0.78 \\
(0.49 \text { to } 1.24)\end{array}$ & $\begin{array}{c}0.94 \\
(0.44 \text { to } 2.02)\end{array}$ & - & $\begin{array}{c}0.88 \\
\text { (0.49 to } 1.58)\end{array}$ & $\begin{array}{c}1.42 \\
\text { (0.84 to } 2.4)\end{array}$ & $\begin{array}{c}0.94 \\
\text { (0.67 to } 1.32)\end{array}$ \\
\hline Venlafaxine & $\begin{array}{c}0.99 \\
\text { (0.74 to } 1.32)\end{array}$ & $\begin{array}{c}1.3 \\
(0.62 \text { to } 2.82)\end{array}$ & $\begin{array}{c}0.87 \\
\text { (0.38 to } 2.01)\end{array}$ & $\begin{array}{c}0.77 \\
\text { (0.45 to } 1.32)\end{array}$ & $\begin{array}{c}0.93 \\
(0.46 \text { to } 1.96)\end{array}$ & $\begin{array}{c}1.06 \\
\text { (0.76 to } 1.49)\end{array}$ & $\begin{array}{c}0.87 \\
\text { (0.53 to } 1.5)\end{array}$ & $\begin{array}{c}1.41 \\
(0.92 \text { to } 2.25)\end{array}$ & - \\
\hline Placebo & $\begin{array}{c}0.45 \dagger \\
(0.38 \text { to } 0.54)\end{array}$ & $\begin{array}{c}0.67 \\
(0.39 \text { to } 1.14)\end{array}$ & $\begin{array}{c}0.27 \dagger \\
\text { (0.09 to } 0.81)\end{array}$ & $\begin{array}{c}0.40 \dagger \\
(0.24 \text { to } 0.66)\end{array}$ & $\begin{array}{c}0.48 \dagger \\
(0.30 \text { to } 0.77)\end{array}$ & $\begin{array}{c}0.52 \dagger \\
(0.39 \text { to } 0.68)\end{array}$ & $\begin{array}{c}0.45 \dagger \\
(0.33 \text { to } 0.62)\end{array}$ & $\begin{array}{c}0.81 \\
(0.64 \text { to } 1.08)\end{array}$ & $\begin{array}{c}0.53 \dagger \\
(0.45 \text { to } 0.61)\end{array}$ \\
\hline
\end{tabular}

${ }^{*} \mathrm{OR}>1$ favours UK licensed treatment (or placebo) in left hand column; OR $<1$ favours treatment along top.

†Significant at $\mathrm{P}<0.05$.

comparison data (the remaining studies were of active treatment versus placebo). Furthermore, not all of these studies reported results of the direct comparisons for each of the outcome measures of interest. Of the 18 possibilities (six direct comparisons $\times$ three outcomes) there were 14 pieces of direct evidence reported, 13 of which were deemed to be consistent with the indirect evidence.

\section{Response}

In the primary probabilistic analysis, fluoxetine was ranked first for response. Figure 4 shows the percentage probability of each treatment being ranked the most effective for response. Fluoxetine had the greatest probability of being the most efficacious treatment (probability 62.9\%). In a subanalysis considering response data for UK licensed treatments (see table 1), duloxetine was ranked first (third across all treatments), though it had a only $2.7 \%$ probability of being the most effective treatment for response (fig 4).

Table 2 shows the results of the secondary frequentist analyses, comparing each active treatment (and placebo) for response. These analyses showed that all treatments were favoured over placebo (odds ratio $<1)$. The difference between treatments and placebo was significant (table 2), except in comparisons with escitalopram (odds ratio $0.67,95 \%$ confidence interval 0.39 to 1.14$)$ and tiagabine $(0.81,0.64$ to 1.08$)$.

In contrast with comparisons with placebo, there were few significant differences in terms of response when we compared UK licensed treatments with "active" treatments. The only significant difference was for the comparison between duloxetine and tiagabine, which favoured duloxetine $(1.62,1.01$ to 2.55$)$.

\section{Remission}

When we ranked all active treatments in terms of remission (table 1), fluoxetine was ranked highest, with a $60.6 \%$ probability of being the most efficacious treatment for this outcome (fig 4). In the subanalysis of UK licensed treatments, escitalopram was ranked first (second across all treatments) in terms of remission (table 1), having a $26.7 \%$ probability of being the most efficacious (fig 4).

Table 3 reports the results of the secondary analyses in terms of remission. These analyses showed that all active treatments were favoured over placebo (odds ratio $<1$ ) in terms of inducing remission. With the exception of tiagabine $(0.76,0.57$ to 1.01$)$, the difference between treatments was significant. When we compared UK licensed treatments with other active treatments, venlafaxine was superior to tiagabine (1.74, 1.07 to 2.95); there were, however, no significant differences between the other treatments.

\section{Withdrawals because of adverse events}

The primary analysis allowed treatments to be ranked in terms of tolerability, measured as the percentage of patients who withdrew from studies because of adverse events (table 1). Sertraline was ranked first (that is, it was associated with the lowest percentage of withdrawals), with a $49.3 \%$ probability of being the best for this

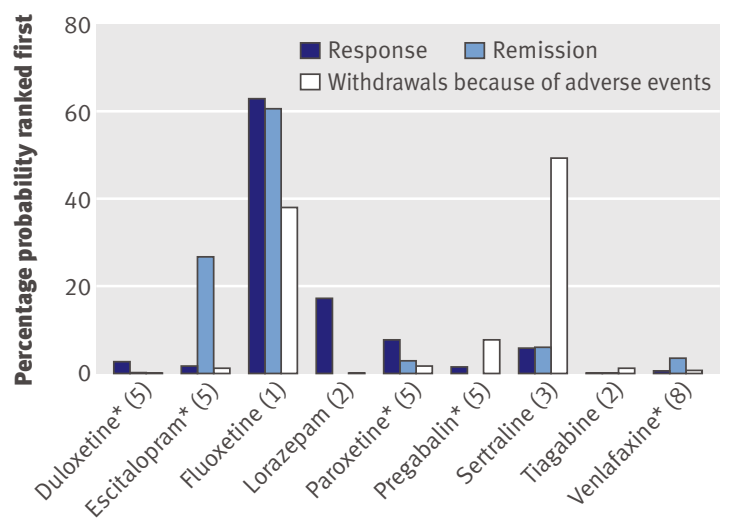

Fig 4 | Probabilistic analysis showing percentage probability of each treatment being ranked first by outcome measure. Numbers in parentheses indicate number of trials analysed for each treatment. Remission data were not available for lorazepam and pregabalin. *Drug licensed in UK 
Table $3 \mid$ Results of secondary mixed treatment meta-analyses comparing UK licensed treatments with other treatments considered, in terms of remission (proportion of patients with final Hamilton anxiety scale score $\leq 7)$. Figures are odds ratios* $(95 \%$ confidence intervals)

\begin{tabular}{|c|c|c|c|c|c|c|c|}
\hline $\begin{array}{l}\text { UK licensed } \\
\text { treatments } \\
\text { and placebo }\end{array}$ & Duloxetine & Escitalopram & Fluoxetine & Paroxetine & Sertraline & Tiagabine & Venlafaxine \\
\hline Duloxetine & - & $0.62(0.29$ to 1.32$)$ & $0.57(0.28$ to 1.43$)$ & 0.85 (0.5 to 1.46$)$ & 0.9 (0.43 to 1.84$)$ & $1.42(0.88$ to 2.25$)$ & 0.83 (0.64 to 1.08$)$ \\
\hline Escitalopram & $1.61(0.73$ to 3.5$)$ & - & $0.72(0.15$ to 3.78$)$ & $1.38(0.59$ to 3.3$)$ & $1.43(0.52$ to 3.84$)$ & $2.21(0.95$ to 5.06$)$ & $1.31(0.56$ to 2.81$)$ \\
\hline Paroxetine & 1.18 (0.68 to 2.03$)$ & $0.74(0.32$ to 1.78$)$ & $0.49(0.11$ to 2.47$)$ & - & 1.06 (0.46 to 2.42$)$ & $1.66(0.89$ to 3.03$)$ & $0.96(0.52$ to 1.64$)$ \\
\hline Venlafaxine & $1.2(0.93$ to 1.56$)$ & 0.77 (0.37 to 1.7$)$ & 0.71 (0.3 to 1.64$)$ & 1.05 (0.62 to 1.9$)$ & 1.1 (0.52 to 2.33$)$ & $1.74 \dagger$ (1.07 to 2.95$)$ & - \\
\hline Placebo & $0.53 \dagger(0.47$ to 0.65$)$ & $0.34 \dagger(0.20$ to 0.57$)$ & $0.24 \dagger(0.06$ to 0.97$)$ & $0.45 \dagger(0.33$ to 0.63$)$ & $0.78 \dagger(0.29$ to 0.78$)$ & $0.76(0.57$ to 1.01$)$ & $0.45 \dagger(0.37$ to 0.55$)$ \\
\hline
\end{tabular}

outcome (fig 4). Lorazepam was ranked last in terms (that is, it was associated with the highest percentage of study withdrawals).

In the subanalysis of UK licensed treatments (see table 1), pregabalin was ranked first (second across all treatments), with a $7.7 \%$ probability of being the best tolerated of all treatments considered, and duloxetine was ranked last in terms of withdrawals because of adverse events (fig 4).

Table 4 shows the results of the secondary analyses for withdrawals because of adverse events: placebo was favoured over all active treatments . The difference between treatments was significant except for comparisons with fluoxetine $(1.54,0.13$ to 16.67$)$ and sertraline $(1.12,0.61$ to 2.04$)$. When we compared withdrawals because of adverse events for UK licensed treatments and other active treatments, pregabalin was superior to duloxetine $(1.97,1.07$ to 3.63$)$ and lorazepam (1.92, 1.17 to 3.16$)$ and sertraline was superior to duloxetine $(0.34,0.13$ to 0.83$)$. There were no significant differences between any of the remaining comparisons (table 4).

There were insufficient data to look at funnel plots for small study effects (which could be caused by publication bias) as this is recommended only when there are at least 10 studies. ${ }^{61}$ Using Begg's test we found no evidence of publication bias in any of the analyses, except for withdrawals because of adverse events when we considered all active treatments $(\mathrm{P}=0.005)$.

\section{DISCUSSION}

Principal findings

Primary probabilistic mixed treatment meta-analyses comparing drug treatments for generalised anxiety disorder showed that fluoxetine was ranked first in terms of response and remission and sertraline was ranked first in terms of withdrawals because of adverse events. Guidance from the General Medical Council encourages treatments to be prescribed within their licensed indications, ${ }^{62}$ so we performed subanalyses to assess the comparative efficacy of treatments licensed for generalised anxiety disorder in the UK. In these analyses, duloxetine, escitalopram, and pregabalin were ranked first for response, remission, and withdrawals because of adverse events, respectively. Secondary frequentist mixed treatment meta-analyses showed that all active treatments were favoured over placebo in terms of response and remission, whereas placebo was favoured over all active treatments in terms of tolerability (withdrawals because of adverse events). There were few significant differences between active treatments in terms of response and remission. This might be expected as many of the included studies were powered to find superiority to placebo and non-inferiority to active treatment. As our primary probabilistic analysis did not rely on significant outcomes, however, treatments could still be ranked in terms of effectiveness.

\section{Strengths and weaknesses of the study}

The strength of our analysis rests on its robust and transparent design. Our predefined research question was answered by conducting a systematic literature review of all published randomised controlled trials of drug treatments for generalised anxiety disorder. In addition to a systematic search of electronic databases, we identified further studies, some of which were unpublished, by reviewing the reference lists of published pooled analyses and meta-analyses. Our analysis used standard and prespecified definitions for response and remission, as measured with the observer rated scale for assessing anxiety symptoms (HAM-A). We chose the proportion of patients withdrawing because of adverse events during treatment as the best measure of overall tolerability as no single rating scale for side effects was used across studies. We analysed extracted data using robust statistical methods and our primary probabilistic analysis using a Bayesian approach allowed treatments to be ranked in terms of the three outcomes measured. The Bayesian analysis allowed both direct and indirect data to be combined in a robust and more intuitive way than in a standard frequentist analysis; probabilities are easier to understand and interpret than $\mathrm{P}$ values. Although Bayesian analysis includes a subjective element, this has been minimised, and there was consistency between the direct and mixed treatment evidence.

There were, however, some weaknesses. We did not specifically search for unpublished data, so despite a comprehensive search strategy to identify published studies and any unpublished studies referenced in previous systematic reviews and meta-analyses, there 
Table $4 \mid$ Results of secondary mixed treatment meta-analyses comparing UK licensed treatments with other treatments considered, in terms of percentage of patients withdrawing because of adverse events. Figures are odds ratios* $(95 \%$ confidence intervals)

\begin{tabular}{|c|c|c|c|c|c|c|c|c|c|}
\hline $\begin{array}{l}\text { UK licensed } \\
\text { treatments } \\
\text { and placebo }\end{array}$ & Duloxetine & Escitalopram & Fluoxetine & Lorazepam & Paroxetine & Pregabalin & Sertraline & Tiagabine & Venlafaxine \\
\hline Duloxetine & - & $\begin{array}{c}0.78 \\
(0.36 \text { to } 1.74)\end{array}$ & $\begin{array}{c}0.49 \\
(0.1 \text { to } 2.38)\end{array}$ & $\begin{array}{c}1.46 \\
\text { (0.54 to } 3.92)\end{array}$ & $\begin{array}{c}0.71 \\
(0.32 \text { to } 1.57)\end{array}$ & $\begin{array}{c}0.5 \dagger \\
(0.27 \text { to } 0.91)\end{array}$ & $\begin{array}{c}0.34 \dagger \\
(0.13 \text { to } 0.83)\end{array}$ & $\begin{array}{c}0.74 \\
(0.34 \text { to } 1.56)\end{array}$ & $\begin{array}{c}0.81 \\
\text { (0.55 to 1.19) }\end{array}$ \\
\hline Escitalopram & $\begin{array}{c}1.32 \\
(0.56 \text { to } 2.97)\end{array}$ & - & $\begin{array}{c}0.62 \\
(0.04 \text { to } 6.47)\end{array}$ & $\begin{array}{c}1.91 \\
(0.61 \text { to } 5.58)\end{array}$ & $\begin{array}{c}0.94 \\
(0.36 \text { to } 2.29)\end{array}$ & $\begin{array}{c}0.66 \\
(0.27 \text { to } 1.52)\end{array}$ & $\begin{array}{c}0.44 \\
(0.15 \text { to } 1.22)\end{array}$ & $\begin{array}{c}0.97 \\
\text { (0.38 to } 2.37)\end{array}$ & $\begin{array}{c}0.98 \\
(0.41 \text { to } 2.22)\end{array}$ \\
\hline Paroxetine & $\begin{array}{c}1.4 \\
(0.59 \text { to } 3.43)\end{array}$ & $\begin{array}{c}0.73 \\
\text { (0.3 to } 1.78)\end{array}$ & $\begin{array}{c}0.58 \\
(0.03 \text { to } 8.51)\end{array}$ & $\begin{array}{c}2.03 \\
(0.61 \text { to } 6.95)\end{array}$ & - & $\begin{array}{c}0.67 \\
(0.27 \text { to } 1.69)\end{array}$ & $\begin{array}{c}0.46 \\
(0.16 \text { to } 1.43)\end{array}$ & $\begin{array}{c}1.02 \\
(0.41 \text { to } 2.76)\end{array}$ & $\begin{array}{c}1.05 \\
\text { (0.44 to } 2.62)\end{array}$ \\
\hline Pregabalin & $\begin{array}{c}1.97 \dagger \\
\text { (1.07 to } 3.63)\end{array}$ & $\begin{array}{c}1.58 \\
(0.69 \text { to } 3.57)\end{array}$ & $\begin{array}{c}0.77 \\
\text { (0.16 to } 3.82)\end{array}$ & $\begin{array}{c}1.92 \dagger \\
\text { (1.17 to } 3.16)\end{array}$ & $\begin{array}{c}1.38 \\
(0.62 \text { to } 3.25)\end{array}$ & - & $\begin{array}{c}0.66 \\
(0.26 \text { to } 1.76)\end{array}$ & $\begin{array}{c}1.47 \\
(0.65 \text { to } 3.32)\end{array}$ & $\begin{array}{c}1.57 \\
(0.94 \text { to } 2.62)\end{array}$ \\
\hline Venlafaxine & $\begin{array}{c}1.24 \\
(0.84 \text { to } 1.83)\end{array}$ & $\begin{array}{c}1.07 \\
(0.47 \text { to } 2.34)\end{array}$ & $\begin{array}{c}0.49 \\
(0.11 \text { to } 2.09)\end{array}$ & $\begin{array}{c}1.47 \\
(0.71 \text { to } 3.07)\end{array}$ & $\begin{array}{c}0.94 \\
(0.41 \text { to } 2.05)\end{array}$ & $\begin{array}{c}0.63 \\
\text { (0.38 to } 1.04)\end{array}$ & $\begin{array}{c}0.43 \\
(0.17 \text { to } 1.05)\end{array}$ & $\begin{array}{c}0.99 \\
(0.46 \text { to } 2.11)\end{array}$ & - \\
\hline Placebo & $\begin{array}{c}3.57 \dagger \\
\text { (2.50 to } 5.26)\end{array}$ & $\begin{array}{c}2.86 \dagger \\
\text { (1.64 to } 4.76)\end{array}$ & $\begin{array}{c}1.54 \\
(0.13 \text { to } 16.67)\end{array}$ & $\begin{array}{c}2.26 \dagger \\
(2.5 \text { to } 11.11)\end{array}$ & $\begin{array}{c}5.26 \dagger \\
\text { (2.50 to } 11.11)\end{array}$ & $\begin{array}{c}1.79 \dagger \\
\text { (1.15 to } 2.78)\end{array}$ & $\begin{array}{c}1.12 \\
(0.61 \text { to } 2.04)\end{array}$ & $\begin{array}{c}2.56 \dagger \\
\text { (1.64 to } 4.0)\end{array}$ & $\begin{array}{l}2.70 \dagger \\
\text { (1.79 to } 4.0)\end{array}$ \\
\hline
\end{tabular}

${ }^{*} \mathrm{OR}>1$ favours UK licensed treatment (or placebo) in left hand column; OR $<1$ favours treatment along top.

†Significant at $\mathrm{P}<0.05$.

could be unpublished studies we did not identify. All included studies were sponsored by manufacturers and potentially open to bias, though this would probably affect all drugs similarly. The asymmetry that exists in the analysis of withdrawals because of adverse effects could be caused by publication bias but could also be caused by the heterogeneity that exists between studies, not least between the different active treatments considered. The funnel plots also illustrated the difficulty of comparing various treatments in this manner, with two studies having high odds ratios for response compared with most studies. One of these was the fluoxetine study. As this was the only study involving fluoxetine, it is uncertain whether this study is an outlier because fluoxetine is a more efficacious drug or if it is a positive outlier (high odds ratio) that is not matched with a negative outlier (low odds ratio), which might suggest publication bias. Funnel plots were constructed both with and without the outlying studies.

We used a single reviewer to assess publications during the data selection stages of the systematic review. As eligibility criteria were relatively simple there was limited scope for erroneous exclusion of suitable publications. In addition, the eligibility criteria were sufficiently restrictive to ensure that we included only higher quality publications (that is, only double blind randomised controlled trials) in our meta-analysis. We did not consider covariate effects such as history of previous treatment or study region in the model as these were not explicitly reported in the included studies. Although comorbidity is common in generalised anxiety disorder (particularly with depression and other anxiety disorders), potential participants with relevant comorbidity were excluded from the included studies so we could not examine the effects of comorbid depression or other anxiety disorders on clinical outcomes.

Our analysis also had some limitations that were largely inherent in the evidence available for mixed treatment meta-analyses. For example, placebo was often the common comparator but response rates to placebo in generalised anxiety disorder are highly variable. ${ }^{63}$ This might have affected the strength of such analyses and could have contributed to the lack of significance in many treatment comparisons. The strength and validity of some treatment comparisons were also affected by the limited data used to inform the statistical analyses. For example, we found few randomised controlled trials for comparisons of fluoxetine, sertraline, or tiagabine. For fluoxetine and tiagabine we found only one study (containing links to two treatments of interest) forming the evidence base for the favourable ranking of fluoxetine ${ }^{33}$ and two studies for the unfavourable ranking of tiagabine ${ }^{1823}$ in terms of response and remission.

Finally, although diagnostic checks showed model convergence, we did not perform sensitivity analyses around baseline prior parameterisation and covariance structure for treatment effects. However, different initial values were considered and the respective models were compared to determine if these had any bearing on the output.

\section{Strengths and weaknesses in relation to other studies}

There are limited published data comparing all available drug treatments for generalised anxiety disorder. A similar network meta-analysis published by Cipriani and colleagues in 2009 ranked antidepressant drugs in terms of response and early withdrawals for any reason but this was in patients with depression rather than generalised anxiety disorder. ${ }^{64}$ Our analysis did not identify a single drug (or class of drugs) that could be considered superior to other drugs. This is consistent with the results of another meta-analysis, which was unable to differentiate between the beneficial effects of benzodiazepines and azapirones. ${ }^{10}$ As our primary probabilistic analysis did not rely on significant outcomes, however, the comparative effectiveness of active treatments could still be assessed, based on the probability of each treatment being most effective or first in terms of each outcome. "Response" is a good 

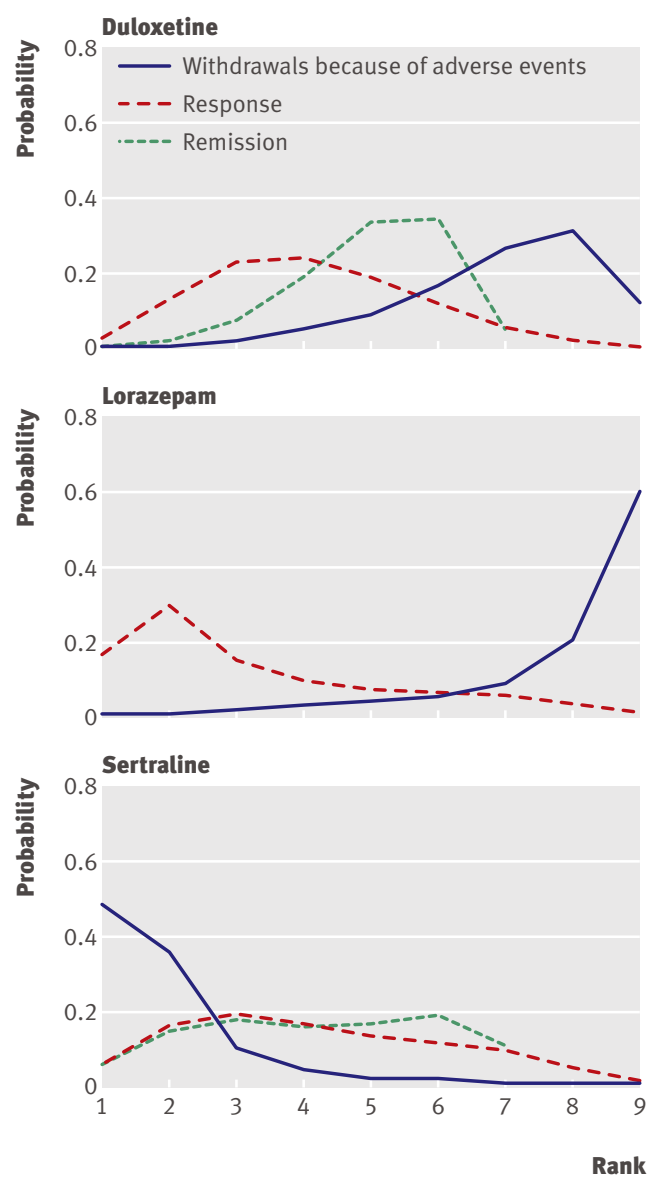

Escitalopram
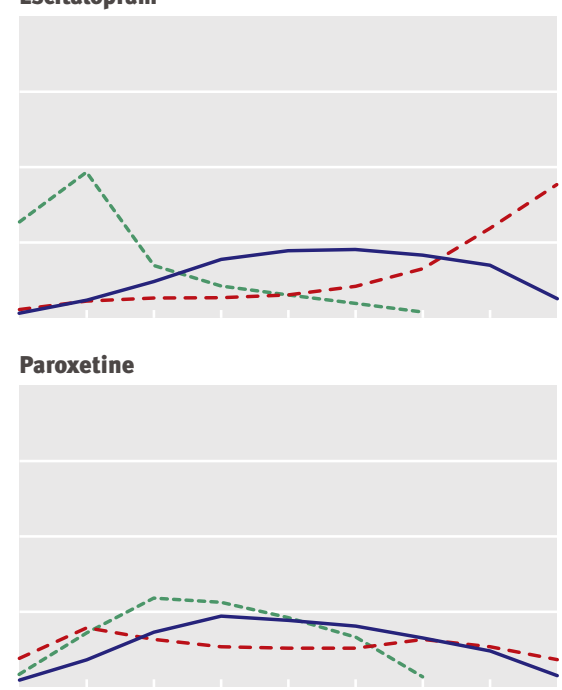

Tiagabine

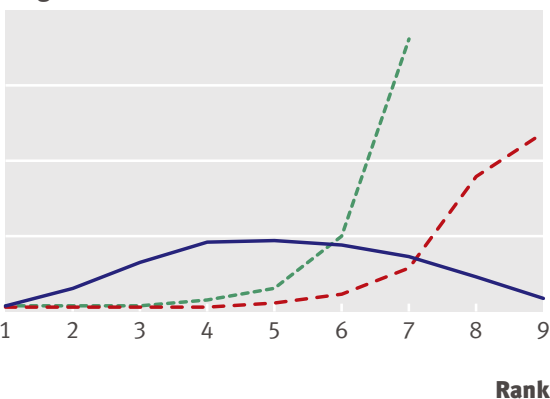

Fluoxetine

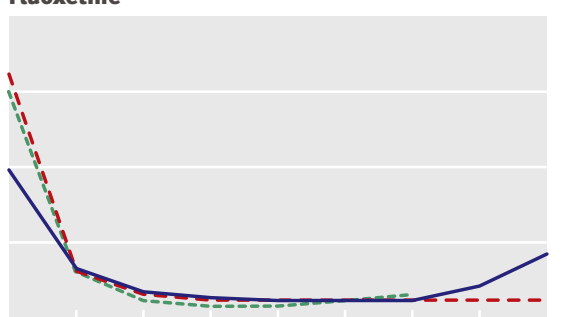

Pregabalin

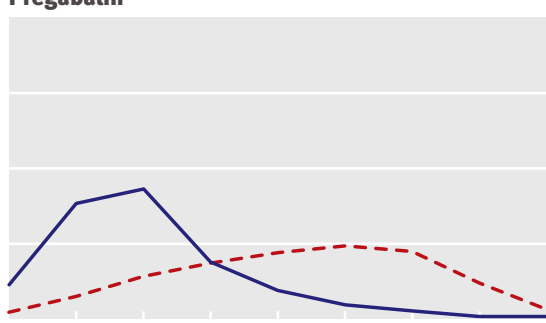

Venlafaxine

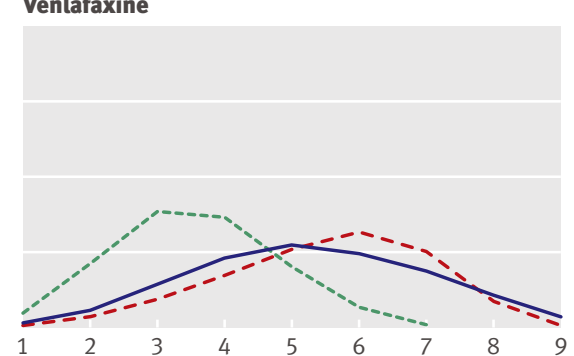

Fig 5 | Individual rankings for outcomes for response, remission, and withdrawals because of adverse events for each of treatments considered. Ranking indicates probability that treatment is first, second, third most effective and so on among nine treatments considered

measure of the reduction in severity of symptoms; "remission" represents another important outcome, as patients who respond might still have troublesome residual symptoms and an increased risk of relapse. ${ }^{6566}$ Our study ranked the selective serotonin reuptake inhibitors fluoxetine and escitalopram first and second, respectively, in terms of remission. This accords with previous $^{7}$ and current ${ }^{67}$ guidelines from the National Institute for Health and Clinical Excellence and a recent comprehensive review of pharmacotherapies, ${ }^{68}$ which both suggest that selective serotonin reuptake inhibitors should be considered as first line treatment because of their favourable efficacy and tolerability. We did not perform a cost effectiveness analysis so cannot comment on efficacy and tolerability benefits in relation to costs. The recent National Institute for Health and Clinical Excellence guideline suggests that sertraline might be the most cost effective drug, based on economic modelling. ${ }^{67}$

\section{Interpretation}

The findings of this meta-analysis suggest that selective serotonin reuptake inhibitors are the most effective drug treatment option for patients with generalised anxiety disorder. This is consistent with previous and current National Institute for Health and Clinical
Excellence guidelines and the results of a supportive analysis, which recommend selective serotonin reuptake inhibitors as first line treatment for long term management. ${ }^{76768}$ In our analysis, fluoxetine was the most efficacious drug in terms of remission, but the limited evidence on which the fluoxetine analysis was based casts doubt on the robustness of this finding. Furthermore, within the European Union the granting of a licence for treatment of generalised anxiety disorder requires proof of both acute efficacy and efficacy over the long term, and neither fluoxetine nor sertraline have proved efficacy in prevention of relapse. In the subanalysis that compared treatments currently licensed for generalised anxiety disorder in the UK, escitalopram was ranked first in terms of symptomatic remission.

Intriguingly, the results relating to the differing measures of response and remission in our meta-analysis do not seem to correlate well. By contrast, in clinical studies, response and remission treatment outcomes correlate highly; by definition, patients achieving remission will also have achieved a response. ${ }^{223639}$ The possible reasons for the lack of correlation in our analysis are that our approach compared response and remission rates across a broad range of clinical studies, in varying settings, and was conducted in groups of 


\section{WHAT IS ALREADY KNOWN ON THIS TOPIC}

Generalised anxiety disorder is a common, typically chronic, and impairing medical condition for which a range of drug and psychological treatments are available

Recent guidelines tend to recommend a selective serotonin reuptake inhibitor for first line treatment on the basis of benefit in reducing anxiety symptoms with generally mild side effects, but the comparative efficacy and tolerability of treatments is uncertain

\section{WHAT THIS STUDY ADDS}

In this mixed treatment meta-analysis fluoxetine was ranked first for response and remission and sertraline was ranked first for tolerability

Among treatments licensed specifically for generalised anxiety disorder in the UK, duloxetine, escitalopram, and pregabalin might offer some advantages over venlafaxine and paroxetine

patients with differing severity of symptoms and undergoing treatment with varying regimens. As a result, the data informing our meta-analysis did not represent a discrete or continuous population and some studies included in our analysis reported response rates only, with no remission data. Furthermore there was no evidence of a correlation between baseline HAM-A score and either the percentage of patients achieving a response or the percentage achieving remission ( $\rho=0.09$ and $\rho=-0.05$, respectively).

The current evidence base used to inform this metaanalysis was limited. There were few studies directly comparing active treatments (that is, head to head studies). In addition, we could evaluate only the initial phase of treatment (6-8 weeks), whereas generalised anxiety disorder is generally regarded as a long term condition requiring long term treatment.

\section{Unanswered questions and future research}

A more complex model with incorporation of covariate effects could be implemented in further work to elucidate and therefore adjust for other factors that might have an impact on parameters as these would manage any variation between the direct and indirect evidence. Finally, we identified relatively little published evidence on patient reported outcomes such as quality of life in generalised anxiety disorder. These limitations in the evidence base could form the rationale for future research investigating comparative effectiveness of treatments used in generalised anxiety disorder over the longer term.

Contributors: DB and DT provided specialist input regarding the research question and scope of the analyses, performed critical review of results, and assisted in the development of the manuscript from first draft to final submitted version. RL was involved in finalising the scope of the analyses, first and second pass screening of articles, and data selection stages of the systematic review. In addition, he performed all statistical analyses and assisted in drafting the manuscript. RW was involved in first and second pass screening of articles and in data selection stages of the systematic review and assisted in drafting the manuscript. All authors approved the final version of the manuscript. Gillian Sibbring is an employee of Complete Medical Group who undertook project management and critical review of the manuscript during all stages of its preparation. DB is guarantor.

Funding: This study was funded by Lundbeck, who commissioned RL, RW, and Gillian Sibbring at Complete Medical Group to conduct the systematic review and meta-analysis, and prepare the manuscript. Lundbeck had input in the concept and design of the study, but it was conducted and reported independently of the company and the authors had final responsibility for the decision to submit for publication. Competing interests: All authors have completed the Unified Competing Interest form at www.icmje.org/coi_disclosure.pdf (available on request from the corresponding author) and declare that DT, RL, and RW have support from Lundbeck for the submitted work; DB holds or has held research grants (on behalf of the University of Southampton) from Cephalon, Eli Lilly, F Hoffmann-La Roche, GlaxoSmithKline, Lundbeck, Organon, Pfizer, Pharmacia, and Wyeth; he has neither received nor wil seek financial reimbursement for his role in this study; DT holds or has held research grants (on behalf of King's College London) from Servier; he has received financial recompense for the time spent away from his paid employment to contribute to this study; when the work was conducted, both RL and RW were employees of Complete Medical Group, who received funding from Lundbeck to conduct the study and prepare the manuscript ( $R L$ is no longer an employee of Complete Medical Group). DB has had specified relationships in the previous 3 years with Asahi Kasei Pharma, AstraZeneca, Cephalon, Eli Lilly, F Hoffmann-La Roche, GlaxoSmithKline, Lundbeck, Organon, Pharmacia, Pierre Fabre, Pfizer, Servier, Sumitomo, and Wyeth; DT has had specified relationships in the previous 3 years with Eli Lilly, Informa Healthcare, Lundbeck, Pfizer, and Servier. As an employee of Complete Medical Group, RL has received funding in the previous 3 years from AstraZeneca.

Ethical approval: Not required.

Data sharing: Technical appendix, statistical code, and dataset available from Gillian Sibbring at Complete Medical Group

(gillian.sibbring@complete-grp.com).

1 Allgulander C. Generalized anxiety disorder: what are we missing? Eur Neuropsychopharmacol 2006;16:S101-8.

2 Hoffman DL, Dukes EM, Wittchen H-U. Human and economic burden of generalized anxiety disorder. Depress Anxiety 2008;25:72-90.

3 Wittchen H-U, Kessler RC, Beesdo K, Krause P, Höfler M, Hoyer J. Generalized anxiety and depression in primary care: prevalence, recognition, and management. / Clin Psychiatry 2002;63(suppl 8):24-34.

4 Maier W, Gänsicke M, Freyberger HJ, Linz M, Heun R, Lecrubier Y. Generalized anxiety disorder (ICD-10) in primary care from a crosscultural perspective: a valid diagnostic entity? Acta Psychiatr Scand 2000;101:29-36.

5 Baldwin DS, Waldman S, Allgulander C. Evidence-based pharmacotherapy of generalized anxiety disorder. Int J Neuropsychopharmacol 2011; Jan7:1-14. epub ahead of print.

6 Bandelow B, Zohar J, Hollander E, Kasper S, Möller HJ, WFSBP Task Force on Treatment Guidelines for Anxiety O-CaP-TSD. World Federation of Societies of Biological Psychiatry (WFSBP) guidelines for the pharmacological treatment of anxiety, obsessive-compulsive and post-traumatic stress disorders-first revision. World J Biol Psychiatry 2008;9:248-312.

7 National Institute for Health and Clinical Excellence. NICE clinical guidance 22 (amended). Anxiety (amended). Management of anxiety (panic disorder, with or without agoraphobia, and generalised anxiety disorder) in adults in primary, secondary and community care. April 2007. www.nice.org.uk/nicemedia/pdf/ CG022NICEguidelineamended.pdf.

8 Martin JLR, Sainz-Pardo M, Furukawa TA, Martin-Sanchez E, Seoane T, Galan C. Review: benzodiazepines in generalized anxiety disorder: heterogeneity of outcomes based on a systematic review and meta-analysis of clinical trials. J Psychopharmacol 2007;21:774-82.

9 Schmitt R, Gazalle FK, de Lima MS, Cunha A, Souza J, Kapczinski F. The efficacy of antidepressants for generalized anxiety disorder: a systematic review and meta-analysis. Rev Bras Psiquiatr 2005;27:18-24

10 Mitte K, Noack P, Steil R, Hautzinger M. A meta-analytic review of the efficacy of drug treatment in generalized anxiety disorder. / Clin Psychopharmacol 2005;25:141-50.

11 Salanti G, Higgins JPT, Ades AE, loannidis JPA. Evaluation of networks of randomized trials. Stat Methods Med Res 2008;17:279-301.

12 Datastar. Dialog DataStar. 2009. www.datastarweb.com/.

13 Cochrane Collaboration. UK Cochrane Centre. 2009. http:// cochrane.co.uk/en/index.html.

14 Lunn DJ, Thomas A, Best N, Spiegelhalter D. WinBUGS-a Bayesian modelling framework: concepts, structure, and extensibility. Stat Comput 2000;10:325-37.

15 Caldwell DM, Ades AE, Higgins JPT. Simultaneous comparison of multiple treatments: combining direct and indirect evidence. $B M$ 2005;331:897-900.

16 Sutton AJ, Abrams KR. Bayesian methods in meta-analysis and evidence synthesis. Stat Methods Med Res 2001;10:277-303. 
17 Nicolini H, Bakish D, Duenas H, Spann M, Erickson J, Hallberg C, et al. Improvement of psychic and somatic symptoms in adult patients with generalized anxiety disorder: examination from a duloxetine, venlafaxine extended-release and placebo-controlled trial. Psychol Med 2009;39:267-76.

18 Pollack MH, Tiller J, Xie F, Trivedi MH. Tiagabine in adult patients with generalized anxiety disorder: results from 3 randomized, doubleblind, placebo-controlled, parallel-group studies. J Clin Psychopharmacol 2008;28:308-16.

19 Rynn M, Russell J, Erickson J, Detke MJ, Ball S, Dinkel J, et al. Efficacy and safety of duloxetine in the treatment of generalized anxiety disorder: a flexible-dose, progressive-titration, placebo-controlled trial. Depress Anxiety 2008;25:182-9.

20 Brawman-Mintzer O, Knapp RG, Rynn M, Carter RE, Rickels K. Sertraline treatment for generalized anxiety disorder: a randomized, double-blind, placebo-controlled study. J Clin Psychiatry 2006;67:874-81.

21 Montgomery SA, Tobias K, Zornberg GL, Kasper S, Pande AC. Efficacy and safety of pregabalin in the treatment of generalized anxiety disorder: a 6-week, multicenter, randomized, double-blind, placebocontrolled comparison of pregabalin and venlafaxine. J Clin Psychiatry 2006;67:771-82.

22 Wan GJ, Zhang HF, Tedeschi MA, Hackett D. Estimation of symptomfree days in generalized anxiety disorder. Curr Med Res Opin 2006;22:587-91.

23 Pollack MH, Roy-Byrne PP, Van Ameringen M, Snyder H, Brown C, Ondrasik J, et al. The selective GABA reuptake inhibitor tiagabine fo the treatment of generalized anxiety disorder: results of a placebocontrolled study. J Clin Psychiatry 2005;66:1401-8.

24 Rickels K, Pollack MH, Feltner DE, Lydiard RB, Zimbroff DL, Bielski RJ, et al. Pregabalin for treatment of generalized anxiety disorder: a 4week, multicenter, double-blind, placebo-controlled trial of pregabalin and alprazolam. Arch Gen Psychiatry 2005;62:1022-30.

25 Bielski RJ, Bose A, Chang C-C. A double-blind comparison of escitalopram and paroxetine in the long-term treatment of generalized anxiety disorder. Ann Clin Psychiatry 2005;17:65-9.

26 Ball SG, Kuhn A, Wall D, Shekhar A, Goddard AW. Selective serotonin reuptake inhibitor treatment for generalized anxiety disorder: a double-blind, prospective comparison between paroxetine and sertraline. J Clin Psychiatry 2005;66:94-9.

27 Steiner M, Allgulander C, Ravindran A, Kosar H, Burt T, Austin C Gender differences in clinical presentation and response to sertraline treatment of generalized anxiety disorder. Hum Psychopharmacol Clin Exp 2005;20:3-13.

28 Nimatoudis I, Zissis NP, Kogeorgos J, Theodoropoulou S, Vidalis A, Kaprinis G. Remission rates with venlafaxine extended release in Greek outpatients with generalized anxiety disorder. A double-blind, randomized, placebo controlled study. Int Clin Psychopharmacol 2004;19:331-6.

29 Lenox-Smith AJ, Reynolds A. A double-blind, randomised, placebo controlled study of venlafaxine $\mathrm{XL}$ in patients with generalised anxiety disorder in primary care. Br J Gen Pract 2003;53:772-7.

30 Feltner DE, Crockatt JG, Dubovsky SJ, Cohn CK, Shrivastava RK, Targum SD, et al. A randomized, double-blind, placebo-controlled, fixed-dose, multicenter study of pregabalin in patients with generalized anxiety disorder. J Clin Psychopharmacol 2003;23:240-9.

31 Rickels K, Zaninelli R, McCafferty J, Bellew K, Iyengar M, Sheehan D. Paroxetine treatment of generalized anxiety disorder: a double-blind, placebo-controlled study. Am / Psychiatry 2003;160:749-56.

32 Pande AC, Crockatt JG, Feltner DE, Janney CA, Smith WT, Weisler R, et al. Pregabalin in generalized anxiety disorder: a placebocontrolled trial. Am J Psychiatry 2003;160:533-40.

33 Silverstone PH, Salinas E. Efficacy of venlafaxine extended release in patients with major depressive disorder and comorbid generalized anxiety disorder. / Clin Psychiatry 2001;62:523-9.

34 Pollack MH, Zaninelli R, Goddard A, McCafferty JP, Bellew KM, Burnham DB, et al. Paroxetine in the treatment of generalized anxiety disorder: results of a placebo-controlled, flexible-dosage trial. J Clin Psychiatry 2001;62:350-7.

35 Davidson JRT, DuPont RL, Hedges D, Haskins JT. Efficacy, safety, and tolerability of venlafaxine extended release and buspirone in outpatients with generalized anxiety disorder. J Clin Psychiatry 1999;60:528-35.

36 Hartford JT, Endicott J, Kornstein SG, Allgulander C, Wohlreich MM, Russell JM, et al. Implications of pain in generalized anxiety disorder: efficacy of duloxetine. Prim Care Companion J Clin Psychiatry 2008;10:197-204

37 Koponen H, Allgulander C, Erickson J, Dunayevich E, Pritchett $\mathrm{Y}$, Detke MJ, et al. Efficacy of duloxetine for the treatment of generalized anxiety disorder: implications for primary care physicians. Prim Care Companion J Clin Psychiatry 2007;9:100-7.

38 Hartford J, Kornstein S, Liebowitz M, Pigott T, Russell J, Detke M, et al. Duloxetine as an SNRI treatment for generalized anxiety disorder: results from a placebo and active-controlled trial. Int Clin Psychopharmacol 2007;22:167-74.

39 Davidson JRT, Bose A, Korotzer A, Zheng H. Escitalopram in the treatment of generalized anxiety disorder: double-blind, placebo controlled, flexible-dose study. Depress Anxiety 2004;19:234-40.

40 Baldwin DS, Huusom AKT, Mæhlum E. Escitalopram and paroxetine in the treatment of generalised anxiety disorder. Br J Psychiatry 2006;189:264-72.

41 Data on file, H. Lundbeck A/S. Flexible dose comparison of the safety and efficacy of Lu 26-054 (escitalopram) and placebo in the treatment of generalised anxiety disorder. 2005;SCT-MD-05.

42 Data on file, H. Lundbeck A/S. Flexible-dose comparison of the safety and efficacy of escitalopram and placebo in the treatment of generalised anxiety disorder. 2005;SCT-MD-06.

43 Montgomery S, Chatamra K, Pauer L, Whalen E, Baldinetti F. Efficacy and safety of pregabalin in elderly people with generalised anxiety disorder. Br J Psychiatry 2008;193:389-94.

44 Adams JB, Pyke RE, Costa J, Cutler NR, Schweizer E, Wilcox CS, et al. A double-blind, placebo-controlled study of a CCK-B receptor antagonist, Cl-988, in patients with generalized anxiety disorder. J Clin Psychopharmacol 1995;15:428-34.

45 Bourin M, Malinge M. Controlled comparison of the effects and abrupt discontinuation of buspirone and lorazepam. Prog NeuroPsychopharmacol Biol Psychiat 1995;19:567-75.

46 Lee S-T, Park JH, Kim M. Efficacy of the $5-\mathrm{HT}_{1 \mathrm{~A}}$ agonist, buspirone hydrochloride, in migraineurs with anxiety: a randomized, prospective, parallel group, double-blind, placebo-controlled study. Headache 2005;45:1004-11.

47 Sramek JJ, Tansman M, Suri A, Hornig-Rohan M, Amsterdam JD, Stahl SM, et al. Efficacy of buspirone in generalized anxiety disorder with coexisting mild depressive symptoms. J Clin Psychiatry 1996;57:287-91.

48 Aliyev NA, Aliyev ZN. Valproate (depakine-chrono) in the acute treatment of outpatients with generalized anxiety disorder without psychiatric comorbidity: randomized, double-blind placebocontrolled study. Eur Psychiatry 2008;23:109-14.

49 Andreatini R, Sartori VA, Seabra MLV, Leite JR. Effect of valepotriates (valerian extract) in generalized anxiety disorder: a randomized placebo-controlled pilot study. Phytother Res 2002;16:650-4.

50 Ansseau M, Olié J-P, von Frenckell R, Jourdain G, Stehle B, Guillet P. Controlled comparison of the efficacy and safety of four doses of suriclone, diazepam, and placebo in generalized anxiety disorder. Psychopharmacology (Berl) 1991;104:439-43.

51 Boerner RJ, Sommer H, Berger W, Kuhn U, Schmidt U, Mannel M. Kava-Kava extract LI 150 is as effective as opipramol and buspirone in generalised anxiety disorder-an 8-week randomized, doubleblind multi-centre clinical trial in 129 out-patients. Phytomedicine 2003;10(suppl 4):38-49.

52 Brawman-Mintzer O, Knapp RG, Nietert PJ. Adjunctive risperidone in generalized anxiety disorder: a double-blind, placebo-controlled study. J Clin Psychiatry 2005;66:1321-5.

53 Bystritsky A, Kerwin L, Feusner JD, Vapnik T. A pilot controlled trial of bupropion XL versus escitalopram in generalized anxiety disorder. Psychopharmacol Bull 2008;41:46-51.

54 Dunayevich E, Erickson J, Levine L, Landbloom R, Schoepp DD, Tollefson GD. Efficacy and tolerability of an mGlu2/3 agonist in the treatment of generalized anxiety disorder. Neuropsychopharmacology 2008;33:1603-10.

55 Linden M, Hadler D, Hofmann S. Randomized, double-blind, placebo-controlled trial of the efficacy and tolerability of a new isoindoline derivative (DN-2327) in generalized anxiety. Hum Psychopharmacol 1997;12:445-52.

56 Llorca P-M, Spadone C, Sol O, Danniau A, Bougerol T, Corruble E, et al. Efficacy and safety of hydroxyzine in the treatment of generalized anxiety disorder: a 3-month double-blind study. J Clin Psychiatry 2002;63:1020-7.

57 Naukkarinen H, Raassina R, Penttinen J, Ahokas A, Jokinen R, Koponen $\mathrm{H}$, et al. Deramciclane in the treatment of generalized anxiety disorder: a placebo-controlled, double-blind, dose-finding study. Eur Neuropsychopharmacol 2005;15:617-23.

58 Pollack MH, Simon NM, Zalta AK, Worthington JJ, Hoge EA, Mick E, et al. Olanzapine augmentation of fluoxetine for refractory generalized anxiety disorder: a placebo controlled study. Bio Psychiatry 2006;59:211-5.

59 Simon NM, Connor KM, LeBeau RT, Hoge EA, Worthington IJ III, Zhang W, et al. Quetiapine augmentation of paroxetine CR for the treatment of refractory generalized anxiety disorder: preliminary findings. Psychopharmacology (Berl) 2008;197:675-81.

60 Stein DJ, Ahokas AA, de Bodinat C. Efficacy of agomelatine in generalized anxiety disorder: a randomized, double-blind, placebocontrolled study. J Clin Psychopharmacol 2008;28:561-6.

61 Cochrane Collaboration. Cochrane handbook for systematic reviews of interventions. 2009. www.cochrane-handbook.org/. 
62 General Medical Council. Good practice in prescribing medicines. 2008. www.gmc-uk.org/guidance/current/library/ prescriptions_faqs.asp\#5c.

63 Piercy MA, Sramek JJ, Kurtz NM, Cutler NR. Placebo response in anxiety disorders. Ann Pharmacother 1996;30:1013-9.

64 Cipriani A, Furukawa TA, Salanti G, Geddes JR, Higgins JPT, Churchill R, et al. Comparative efficacy and acceptability of 12 newgeneration antidepressants: a multiple-treatments meta-analysis. Lancet 2009;373:746-58.

65 Pollack MH. Optimizing pharmacotherapy of generalized anxiety disorder to achieve remission. J Clin Psychiatry 2001;62(suppl 19):20-5.
66 Mandos LA, Reinhold JA, Rickels K. Achieving remission in generalized anxiety disorder. What are the treatment options? 2009. www.psychiatrictimes.com/display/article/10168/1370513.

67 National Institute for Health and Clinical Excellence. Generalised anxiety disorder and panic disorder (with or without agoraphobia) in adults: management in primary, secondary and community care. NICE clinical guideline 113, January 2011. www.nice.org.uk/ nicemedia/live/12147/51542/51542.pdf

68 Hoffman EJ, Mathew SJ. Anxiety disorders: a comprehensive review of pharmacotherapies. Mt Sinai J Med 2008;75:248-62.

Accepted: 20 January 2011 